\title{
A Comparison of Linguistic Errors of Iranian EFL Learners at Two Different Levels of Proficiency
}

\author{
Bahareh Malmir \\ Islamic Azad University, South Tehran Branch, Iran
}

\begin{abstract}
This descriptive case study aimed to analyze syntactical, morphological and lexical errors produced by Iranian EFL learners at two different levels of basic and elementary. The proposed hypothesis predicted that there exist considerable differences between the errors produced by the participants with respect to their origin (interlingual, intralingual or developmental errors) as well as the type of error (lexical or grammatical). To this end, four Iranian EFL learners at basic level and four at elementary level, attending English language classes at Iran Language Institute were chosen using purposeful sampling. A test of proficiency was administered to ensure the participants in each group are homogenous regarding the level of proficiency. The participants' performance in both oral and written activities as well as planned and unplanned ways were meticulously observed and recorded by the researcher in a six-month period. In addition to observation, data were also obtained through interviews and tests given at intervals of every two months to investigate any potential change. The qualitative data were coded, categorized and interpreted cyclically. It was concluded that learners at higher levels of proficiency produced more developmental and intralingual errors than learners at basic levels. Also learners at basic levels produced more interlingual errors. In addition learners at basic levels produced more grammatical errors than learners at elementary levels. On the other hand, learners at elementary level produced more lexical errors.
\end{abstract}

Index Terms - interlingual errors, intralingual errors, developmental errors, lexical errors and grammatical errors

\section{INTRODUCTION}

In the field of second language learning, errors which are the results of lack of knowledge (i.e. lack of competence) have been treated in various ways ranging from complete ignorance to avoidance at all costs. Fortunately, these days, errors are no longer perceived as signs of bad language and learners as criminals committing them. In fact, errors have recently received considerable attention as signs of progress in learning a second language and many instructors and researchers believe that errors are invaluable evidences that tell us much about the underlying system of individual learning. Cordor (1967) asserted that errors provide the researcher with evidence of how language is learnt and also those they serve as devices by which learners discover the rules of language.

The procedure of data collection in error analysis is of prime importance as it can influence the result of error analysis to great extend. Lococo (1976) reported differences in the number and type of errors in samples of learners' language collected by means of free compositions, translation or picture composition. Eliss (2008) lists some of the factors that need to be considered in collecting a sample of learners' language asserting that "unfortunately, many EA studies paid little attention to these factors with the results that they are difficult to interpret and impossible to replicate" (p.47). These factors include: proficiency level, other languages, language learning experience, medium, genre, content, planned and unplanned.

\section{REVIEW OF RELATED LiteRATURE}

\section{A. Identification and Types of Errors}

The definition of error is somehow difficult since different definitions have been presented by various scholars. The chief problem is the criteria which should be considered to determine whether an item can be labeled error or not. According to Eliss (2008), theses criteria may range from grammaticality (i.e. well-formedness) to acceptability. Cordor (1967) makes a distinction between Errors and Mistakes and he defines errors as deviations as a result of lack of knowledge and mistakes as performance phenomena, reflecting processing failure and as a result of memory limitation and lack of automaticity. Errors can also be classified as Overt or Covert. While overt errors are easy to spot because of clear ungrammaticality, covert errors happen when the sentence is correct at the surface level but do not mean what the learners intended them to mean.

Another issue regarding the criteria for defining errors is whether "infelicitous uses of L2 should be considered erroneous. There are instances where a learner produces a form that is grammatical (i.e. conforms to the norms of the 
code) but this may not be the form preferred by native speakers of the code. While there are different classification of errors proposed by different scholars, Cordor's (1974) frame work for describing errors is more promising. He classifies errors according to their systematicity.

1. Presystematic Errors occur when the learner is unaware of the existence of a particular rule in the target language. These are random.

2. Systematic Errors occur when the learner has discovered a rule but it is the wrong one.

3. Post systematic Errors occur when the learner know the correct target language use but uses it inconsistently (i.e. makes a mistake)

In addition to the framework proposed by Cordor (1974), other sources of psycholinguistic errors have been identified by Richards(1971):

1. Interference Errors occur as a result of 'the use of elements from one language while speaking another.

2. Intralingual Errors 'reflect the general characteristics of rule learning such as faulty generalizations, incomplete application of rules and failure to learn conditions under which rules apply.

3. Developmental Errors occur when the learner attempts to build up hypothesis about the target language on the basis of limited experience.

\section{B. Steps in Error Analysis}

Since error analysis was one of the first methods used to investigate learners' language, it achieved considerable popularity in the 1970 and there have been many attempts to make the procedure of error analysis systematic. Whilecritics of EA believe that there is no way of investigating avoidance within EA framework, many scholars still believe that the study of error can pave the way for future understanding of how the underlying system in learners mind work. Eliss(2008)explains the steps for conducting error analysis: According to Eliss(2008), "the first step in carrying out an EA is to collect the a sample of learners language. The sample could consist of natural language use or be elicited either clinically or experimentally. It could also be collected cross-sectionally or longitudinally. The second stage involved identifying errors in the in the sample". Cordor distinguishes errors of competence from mistakes in performance and argues that EA should investigate only errors. Cordor also proposed a procedure for identifying errors by reference to normal, authoritative and plausible interpretations. Eliss (2000) defines "the third stage as description. Two types of descriptive taxonomies have been used: Linguistic and surface strategy. The former provides an indication of the number and proportion of errors in either different levels of language or in specific grammatical categories. The fourth stage Is an attempt to explain the errors pscholinguistically. Errors can result from transfer, intralingual and unique processes".

\section{Empirical Studies}

According to Eliss (2008, p.63), "In 1960s and 1970s, Error Analysis went temporarily out of fashion, as a result of perceived weakness in procedure and its scope. However some work in EA continued and, recently, it has had something of rebirth with the advent of computer based analysis of learner language and it continues to be practiced".

Eliss (2008) lists some recent EA research chief among them is the study conducted by Felix (1981) and Pavesi(1986) in Which they compared the language produced by instructed and naturalistic learners. Bardovi-Harling and Bofman (1989) investigated the differences between a group of learners who successfully passed the Indiana University Placement exam and a group who failed to do so. They examined the nature of the errors which the two groups produced in one part of examination -written compositions- and found unremarkably that the pass group made fewer overall errors than the non pass group and the major differences were in the number of lexical and morphological rather than syntactical errors.

In 1975, Burt conducted a research in which he asked non-expert native speakers to judge comprehensibility of different corrected versions of 300 sentences containing multiple errors. The results of the study revealed that subject found versions in which global errors had been corrected more comprehensible than versions in which local errors had been corrected. In another study, Albrechtsen, Henriksen and farch(1980) had 120 non-expert adult native speakers(e.g. hotel workers in UK:180 British sixth formers) to listen to samples of oral language taken from Grade 10 Danish learners of L2 English and rated each sample using bipolar adjective scale(e.g. easy to understand, difficult to understand).the results of the analysis revealed that the oral texts containing few errors (syntactic as well as lexical) and few communication strategies received positive evaluation. Frequent use of communication strategies had greater negative effect than the number of errors.

Some researchers have investigated the effect of task design and implementation on learners' production.Foster and Skehan (1996) calculated the percentage of error free clauses as a general measure of accuracy in their study of tasks. This measure involved examining each clause to determine whether it contained an error. Mehnert(1998) computed the number of errors per 100 words. Crookes (1989) calculated the percentage of target like use of plurals while Skehan and Foster (1997) examined target like use of vocabulary. Eliss (2008) states that "none of these studies included any report of the kinds of problems with error identification, casting sme doubt about reliability of the accuracy measures they employed".

Eliss (2008) presents a summary of selected evaluation studies. For example in 1987, Santos, selected 40 university professors in physical science and asked them to rank 4 written compositions; in two of them, 5 errors of the marked to 
unmarked kind were inserted and in the other 2, 5eroors of the unmarked to marked kind. The subjects were also asked to underline each error and assess the degree of irritation it aroused. The result of the study revealed no significant difference in rankings of the compositions. Overall unmarked to marked errors were found to be more irritating than marked to unmarked errors. Syntactic errors were also found more irritating than morphological errors.

\section{Statement of the Problem}

Unlike summative tests, which deal with decision making and generalisibilty of test scores, formative assessment aims at identifying the points in which students have difficulty mastering and helping them overcome these obstacles. It is needless to say that teachers and stakeholders are the ones who benefit the most if they can discover more about the underlying system of learning and development of interlanguage in learners learning a second language. While the actual process of learning which is happening in learners mind can't be observed and investigated directly, Errors, which are the explicit manifestations of the learning process, can help us do so. As Lantolf and Poehner (2008,273) stated "assessment and instruction are a single activitythat seeks to simultaneously diagnose and promote learner development by offering learner mediation, a qualitatively different support from feedback". Unfortunately, inability to diagnose the causes of errors and the possible obstacles in the process of learning makes such mediation and feedback unhelpful. In fact, one of the factors that causes failure to learn can be defined as lack of attention to nature of errors produced by learners; errors which seem to have a repeated pattern in every stage of learning and can be exploited as an aid for providing the most appropriate feedback on the process of learning.

\section{E. Purpose of the Study}

While there have been countless numbers of EA studies, "unfortunately, many EA studies paid little attention to factors that need to be considered in collecting sample of learners language" (Eliss, 2008). These factors include learner factors (proficiency level, other languages, language learning experience), language sample (medium, genre, content), and production (Unplanned, planned). The purpose of this study is to address this problem by considering all these relevant factors. Another major problem is that the "majority of EA studies have been cross sectional rather than longitudinal, thus making it difficult to determine accurately the different errors that learners produce at different stages of their development"(Ellis,2008). The present case study which is longitudinal in nature addresses this problem and investigates the changes in nature of errors over a long period of time (six months).In addition; the purpose of this study is to gain a deep understanding of the types, causes and origins of errors produced by Iranian EFL learners at two different levels of proficiency (basic and elementary) and to compare the findings so as to be able to define the patterns of change in the nature of errors produced during the process of learning and come up with some suggestions which should be considered while presenting the new points in classrooms.

The following research question was raised in this study:

1. Do learners' errors produced at two different levels of basic and elementary differ with respect to their origin (interlingual, intralingual or developmental errors) as well as the type of error (lexical or grammatical)

\section{METHOD}

\section{A. Participants}

In this descriptive case study, four Iranian EFL learners at basic level and four at elementary level, attending English language classes at Iran Language Institute (Kermanshah Branch) were chosen using purposeful sampling to guarantee the richness of data. The participants, who were within the age range of 14-30, consisted of 2 male and 2 female within each group (basic and elementary). They were all studying The ILI English Series developed by Iran Language institute.

\section{B. Instrumentation}

This qualitative study used a test constructed by Iran Language Institute as a pretest in order to make sure that all participants in each group are at the same level of proficiency. This study also took advantage of both participant observation in which the observer took part in class activities like the other students and observer observation in which the observer only observed the ongoing process of class room. In addition to pretest and observation, semi-structured interviews and consecutive written tests were used in the ongoing process of data collection. Data were recorded both by the observer taking notes and by a tape recorder.

\section{Procedure}

To conduct this longitudinal study, participants were purposefully chosen so as to ensure that data would provide an in-depth understanding of the issue concerned. A test of proficiency whose reliability and validity had been proven in Iran Language Institute was used as a pretest to guarantee the equivalence of participants in each group regarding their level of proficiency (Basic and Elementary).During these six months the participants, who were actually the learners attending their English class two times a week, were observed and their performance was recorded meticulously by the observer. Errors produced by learners who were involved in the process of learning were recorded, analyzed with regard to its origin and type, and classified. Every two months, a written test accompanied with an interview was administered to the learners in which they were required to produce sentences in the target language and their written and oral 
production were analyzed carefully. Finally, all data obtained were classified and coded to show any possible trend or change in the type and origin of errors produced by learners at these two different levels of proficiency.

\section{Design}

This is a case study which is longitudinal in nature and aims at providing a thick, in-depth description of a phenomenon in a long period of time. In order to have a comprehensible view of the research, the process of data collection continued until saturation happened and the data didn't reveal any new pattern or findings. The longitudinal design of the study helped researcher get a better understanding of the differences and possible patterns of change which paved the way for a full comparison of the groups.

\section{E. Data Analysis}

As in qualitative studies, data analysis was the most demanding section of the study due to the cyclical nature of the data collection and qualitative nature of the findings which required a meticulous investigation of each error produced by learners considering different criteria. The challenge was to make sense of massive amount of data, reduce the volume of information and construct a framework for communicating what the data reveal. To this end the data obtained using multiple instruments were organized and described using the most pertinent features. The data, then, were interpreted answering why questions and explaining the possible reasons. For the interpretation of the data, the researcher used the experience and knowledge attained during years of teaching English as a foreign language along with the experiences of two other raters experienced in the field of foreign language teaching. The validity of the findings was enhanced through the triangulation of the multiple data obtained using different sources of data collection.

\section{RESULTS AND DisCUSSION}

\section{A. Errors at Basic Level According to Origin}

Errors produced by learners as basic level were recorded and classified based on their origin (interlingual, intralingual or developmental errors). At basic levels, about 43 percent of all errors originated in the learners mother tongue obviously due to the fact that students had no other system to rely on while engaging in the process of learning a second language. about 28 percent of the recorded interlingual errors were the results of a comparison between word order of the first language and the second language. Another frequent interlingual errors recorded was the use of indefinite article ' $a$ ' before the nouns beginning with a vowel which was in turn due to the fact that such distinction did not exist in the learners' mother tongue. Other interlingual errors were the omission of 'to' between two main verbs and of course many lexical errors produced as a results of comparison between the first and second language.

While 43 percent of errors produced by the participants at basic levels were classified as interlingual, 38 percents of all errors recorded were judged to be developmental by all the raters. Chief among these developmental errors was the omission of third person singular's' which didn't originate from the learners' mother tongue since it has no equivalent in their native language. Another frequent developmental error recorded was the omission of plural' $\mathrm{s}$ ' endings. This error seemed to be sign of the fact that learners didn't understand the necessity of addition of such item to the plural nouns. This error obviously didn't arise from their native language as far as such a distinction between plural nouns and singular nouns exists in their native language.

Not surprisingly, only 19 percent of all errors produced by the participants were considered to originate from the second language. This was basically due to the fact that basic learners did not enough exposure to the second language system in order to make overgeneralizations. Some example of intralingual errors were the addition of 'to be' verbs before the main verbs in simple present tense or the omission of 'to be' verbs in present continuous tense.

Table 4.1 illustrates the most frequent errors produced by Iranian EFL learners at basic levels with respect to their origins:

TABLE 4.1:

ClassificATION OF ERRORS AT BASIC LEVEL BASED ON THE ORIGIN

\begin{tabular}{|l|l|l|}
\hline Origin & Error & A frequent Example \\
\hline \multirow{4}{*}{ Interlingual Errors } & Word Order & Nouns/adjectives replacement (A girl beautiful) \\
\cline { 2 - 3 } & Omission of indefinite article 'an' & (she is a adorable teacher) \\
\cline { 2 - 3 } & Omission of 'to' between verbs & (I prefer stay home) \\
\cline { 2 - 3 } & Us of 'for' before simple form of the verb & (For feel better, you should go on vacation) \\
\hline Intralingual Errors & To be verb +a main verb (I am go)3 & (Iam go) \\
\cline { 2 - 3 } & Omission of "to be" before a verb + ing & (Iwatching TV) \\
\hline \multirow{3}{*}{ Developmental errors } & Omission of third person singular12 & ( she play tennis with her friends) \\
\cline { 2 - 3 } & Omission of plural "s"5 & (all my friend are tall) \\
\cline { 2 - 3 } & Omission of "to be" before a verb + ing & (I watching TV) \\
\hline
\end{tabular}

\section{B. Errors at Elementary Levels According to Origin}

Errors produced by participants at elementary level were also described and classified considering the origin of errors (interlingual, intralingual or developmental errors). As predicted, the types of errors recorded by the researcher at this level during a period of six months were considerably different with respect to the frequency and origin of them. While 
43 percent of all errors at basic levels originated in the learners' mother tongue, at the elementary level 41 percent of all errors were judged by the raters to be developmental and 35 percent of them were classified as intra lingual by the raters. An example of developmental errors is the wrong usage of words with different parts of speech. Participants frequently made errors due to the fact that they could not differentiate between the actual parts of the speech of the words. In addition, many of the errors recorded reveal the fact that the participants used a grammatical tense wrongly mainly due to the fact that either they had not understood the real use of the tense or they felt more comfortable with the tenses the had learnt earlier.

In addition to developmental errors, 32 percent of all errors were judged to be intralingual resulting from the comparison of the earlier learnt items with newly presented items. It is needless to say that the meticulous analyses of such intralingual errors will yield valuable information about the underlying system of the learners' interlanguage and they should not be considered as ill forms of language that should be prevented at all costs. Much of the data obtained surprisingly supported the idea of U- shape learning in which learners first seemed to a master a linguistic item and then after returning to their earlier state of learning for a short time, they cold produce the linguistic structures correctly. This process simply reveals that learners are constructing their interlanguage through testing hypothesis about the structure of the target language.

In comparison with the Percentage of developmental and intra lingual errors, only a few of the recorded errors in the data obtained could be classified as interlingual. The most repeated example of which were errors resulting from the comparison of lexical meaning of two items in the first and second language. Table 4.2 illustrates the most frequent errors produced by Iranian EFL learners at elementary levels with respect to their origins:

TABLE 4.2:

CLASSIFICATION OF ERRORS AT ELEMENTARY BASED ON THE ORIGIN

\begin{tabular}{|c|c|c|}
\hline Origin & Errors & A frequent Example \\
\hline \multirow[t]{2}{*}{$\begin{array}{l}\text { Developmental } \\
\text { Errors }\end{array}$} & $\begin{array}{l}\text { Wrong usage of words with different parts of } \\
\text { speech }\end{array}$ & $\begin{array}{l}\text { 1.nouns instead of verbs: ( He applause me) } \\
\text { 2.adjectives instead of nouns)they're the same long) } \\
\text { 3.adjaectives instead of adverbs( he writes slow) }\end{array}$ \\
\hline & Wrong usage of grammatical structures & $\begin{array}{l}\text { 1.present tense instead of past tense( I go last July) } \\
\text { 2.past instead of present perfect( I studied English since last summer) }\end{array}$ \\
\hline \multirow{3}{*}{$\begin{array}{l}\text { Intra lingual } \\
\text { Errors }\end{array}$} & Use of auxiliary verbs in present perfect & (She has eaten sushi, does she?) \\
\hline & Addition of 'ly' to make adverbs & $\begin{array}{l}\text { (He walks fastly) Fast }+ \text { ly }=\text { Fastly } \\
\text { ( I waited there Longly) Long }+1 y=\text { Longly }\end{array}$ \\
\hline & $\begin{array}{l}\text { Wrong addition of 'er' and 'more', 'est' and } \\
\text { 'most' for comparatives and Superlatives }\end{array}$ & $\begin{array}{l}\text { ( she is more happy than her sister) More }+ \text { happy }=\text { more happy } \\
\text { (she is the most pretty girl in class) The most }+ \text { pretty }=\text { the most pretty }\end{array}$ \\
\hline $\begin{array}{l}\text { Interlingual } \\
\text { Errors }\end{array}$ & Lexical translation of items in 2 languages & 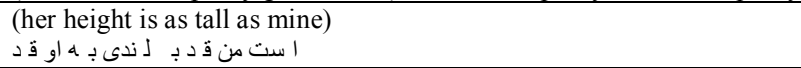 \\
\hline
\end{tabular}

\section{Comparison of the Errors at Two Levels}

After description and classification of errors at each level, this section illustrates the similarities and difference of the types of error recorded at each level. As illustrated in the bar graph 4.1, Participants whose demand of the second language were at basic levels produced more interlingual errors chiefly due to the fact that the system of the first language was the only one learners could rely on while dealing with the second language. While 43 percent of errors produced by basic levels were interlingual, only 24 percent of errors were interlingual at elementary levels where students could rely on their knowledge of second language.Table 4.3 illustrates the Percentage of the errors at both levels of basic and elementary regarding their origins (Interlingual, Intralingual, and Developmental)

TABLE 4.3:

THE PERCENTAGE OF ERROR AT BOTH LEVELS BASED ON THEIR ORIGIN

\begin{tabular}{|l|l|l|}
\hline Origin & Basic Level & Elementary level \\
\hline Interlingual Errors & $43 \%$ & $24 \%$ \\
\hline Intralingual Errors & $19 \%$ & $35 \%$ \\
\hline Developmental Errors & $38 \%$ & $41 \%$ \\
\hline
\end{tabular}

Regarding the intra lingua errors, learners at elementary levels produced more errors than learners at basic levels(35\% at elementary level and 19\% at basic level) all the evidence supports the idea that as learners' level of proficiency improved, they depended less and less on the their knowledge of first language. Moreover, 41 percent of errors at elementary levels and 38 percent of errors at basic levels were classified as developmental errors, supporting the idea that at both levels learners produced errors simply because they were engaged in the process of learning. Bar graph 4.1 illustrates the percentages of errors at both levels based on their origins: 


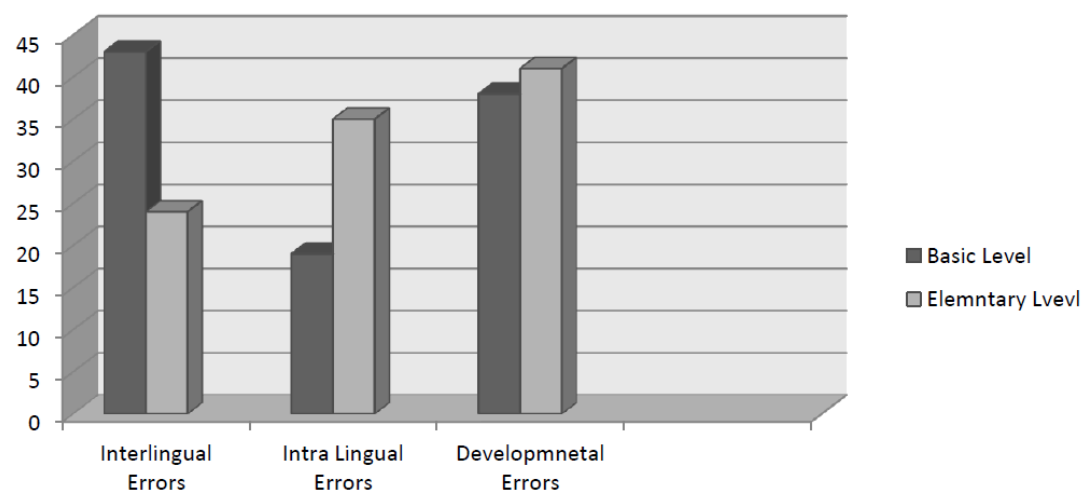

Bar graph 4.1 the Percentages of Errors at Both Levels Based on Their Origins

\section{Investigation of Research Question}

This study aimed at investigating if learners' errors produced at two different levels of basic and elementary differ with respect to their origin (interlingual, intralingual or developmental errors) as well as the type of error (lexical or grammatical errors). Data was collected through multiple instruments and classified by three different raters. The interpretation of data revealed the fact that errors produced by the learners at two different levels of basic and elementary varied greatly regarding their origins. Learners at basic levels produced more interlingual errors, but as their proficiency in English progressed, they produced less and less interlingual errors and errors recorded at higher levels could be better classified as either intralingual or developmental.

The findings also revealed that learners at basic levels produced more grammatical errors than lexical errors. Many of the errors produced at elementary level were lexical reflecting the learners' attempt to use the lexical items in their appropriate context. Chief among these lexical errors were the wrong usage of collocations (using correct proposition after verbs) and lexical errors resulting from the literal translation of words in native language to the target language (e.g. saying 'the bird's house' instead of the 'the bird's nest). Such examples may support the idea that in fact some of the errors produced at higher levels of proficiency is due to the use of compensation strategies. Further studies may investigate the relationship of the two.

\section{DISCUSSION}

As stated before, this qualitative case study investigated the types and origins of errors produced by Iranian EFL learners at two levels of basic and elementary. The results revealed that, in general, learners at elementary levels produced more developmental and intralingual errors than Erooros resulting from the transfer of information from the first language. On the other hand, learners at basic level produced more interlingual errors. Moreover, participants at higher levels produced more lexical errors than grammatical errors while participants at basic levels had more grammatical errors.

Conclusively speaking, no one can deny the importance of teachers' awareness of the nature; causes and types of errors produced by learners at any level as far as errors are the overt manifestations of the underlying system of learners engaged in the process f learning. Although the results obtained from a case study in nature are not as generalizable as the results obtained from quantitative studies, they can provide rich, thick description of an unknown phenomenon which paves the way for further analysis. The results of this are of great value since they can aid stakeholders in the process of learning by providing guidelines on which they can base their feedback to the students leaning.

\section{REFERENCES}

[1] Albrechtsen, D.B.Henriksen, and C.Farch. (1980) Native Speaker Reaction to Learners' Spoken Interlanguage. Language Learning 30:365-396.

[2] Bardovi-Harling,k. and T.Bofman. (1989). Attainment of Syntactic and Morphological Accuracy by Advanced Language Learners, Studies in second language acquisition: 11: 17-34.

[3] Burt,M. (1975). Error Analysis in the adult EFL classroom, TESOL Quarterly9:53-63.

[4] Cordor, S.P. (1967). The Significance of Learners' Errors, International Review of applied Linguistics, 5:161-169

[5] Cordor, S.P. (1974). Error Analysis in J.P. Allen and S.P. Cordor (eds), The Edinburgh Course in Applied Linguistics, Volume 3.London: Oxford University Press.

[6] Crooks, G. (1989). Planning and Inter language Variability, Studies in Second Language Acquistion 11:367-383.

[7] Ellis, R. (2008). the study of Second Language Acquisition, Oxford University Press, Oxford, New York.

[8] Felix, S. (1981). the Effect of Formal Instruction on Second Language Acquisition, Language Learning31:87-112. 
[9] Foster P. and P. Skehan. (1996). the Influence of Planning on Performance in Task Based Learning, Studies in Second Language Acquistion 18/3299-324.

[10] Hornberger, N. H. (eds), (1997). Encyclopedia of Language Education, vol.7, Language Testing and Assessment. New York: Springer, 273-284

[11] Lantolf, J. P. and Poehner, M. E. (2008a). Dynamic Assessment. In Shohamy, E. and Hornberger, N. H (eds), Encyclopedia of Language Education, VOL.7 Language Testing and assessment, Newyork, Springer,273-2.

[12] LoCoco V. (1976). a comparison of Three Methods for the collection of L2 Data : Free Composition, Translation and Picture Description, Working Papers on Composition8:59-86.

[13] Mehnert U. (1998). the Effect of Different Length of Time for Planning on Second Language Learning, Studies in Second Language Acquisition20:52-83.

[14] Richards, J. (1971). a Non Contrastive Approach to Error Analysis, ELT Journal 25: 204-219.

[15] Santos, T. (1987). Markedness Theory and Error Evaluation: an Experimental Study, Applied Linguistics 8:207-218.

Bahareh Malmir holds an M.A. in TEFL from Islamic Azad University, South Tehran Branch, and Iran. She has extensive experience of teaching English as a foreign language. She is an English teacher for Iran Language Institute and also Jahad Language School. Her research interest includes material development and evaluation as well as SLA. 